\title{
BAY 11-7082 Is a Broad-Spectrum Inhibitor with Anti-Inflammatory Activity against Multiple Targets
}

\author{
Jaehwi Lee, ${ }^{1}$ Man Hee Rhee, ${ }^{2}$ Eunji Kim, ${ }^{3}$ and Jae Youl Cho ${ }^{3}$ \\ ${ }^{1}$ College of Pharmacy, Chung-Ang University, Seoul 156-756, Republic of Korea \\ ${ }^{2}$ Laboratory of Physiology \& Cell Signaling, College of Veterinary Medicine, Kyungpook National University, \\ Daegu 702-701, Republic of Korea \\ ${ }^{3}$ Department of Genetic Engineering, Sungkyunkwan University, Suwon 440-746, Republic of Korea
}

Correspondence should be addressed to Man Hee Rhee, rheemh@knu.ac.kr and Jae Youl Cho, jaecho@skku.edu

Received 6 March 2012; Revised 5 April 2012; Accepted 5 April 2012

Academic Editor: Giamila Fantuzzi

Copyright ( $) 2012$ Jaehwi Lee et al. This is an open access article distributed under the Creative Commons Attribution License, which permits unrestricted use, distribution, and reproduction in any medium, provided the original work is properly cited.

BAY 11-7082 (BAY) is an inhibitor of $\kappa$ B kinase (IKK) that has pharmacological activities that include anticancer, neuroprotective, and anti-inflammatory effects. In this study, BAY-pharmacological target pathways were further characterized to determine how this compound simultaneously suppresses various responses. Primary and cancerous (RAW264.7 cells) macrophages were activated by lipopolysaccharide, a ligand of toll-like receptor 4. As reported previously, BAY strongly suppressed the production of nitric oxide, prostaglandin $\mathrm{E}_{2}$, and tumor necrosis factor- $\alpha$ and reduced the translocation of p65, major subunit of nuclear factor- $\kappa \mathrm{B}$, and its upstream signaling events such as phosphorylation of $\mathrm{I} \kappa \mathrm{B} \alpha$, IKK, and Akt. In addition, BAY also suppressed the translocation and activation of activator protein-1, interferon regulatory factor- 3 , and signal transducer and activator of transcription-1 by inhibiting the phosphorylation or activation of extracellular signal-related kinase, p38, TANK-binding protein, and Janus kinase-2. These data strongly suggest that BAY is an inhibitor with multiple targets and could serve as a lead compound in developing strong anti-inflammatory drugs with multiple targets in inflammatory responses.

\section{Introduction}

Inflammatory signals activate inflammatory cells such as blood vessel epithelial cells, macrophages, neutrophils, mast cells, and lymphocytes to produce inflammatory mediators These include cytokines such as interleukin (IL)-1, IL-6, and tumor necrosis factor (TNF)- $\alpha$; chemokines; toxic molecules including nitric oxide (NO); lipidic mediators including prostaglandin $\mathrm{E}_{2}\left(\mathrm{PGE}_{2}\right)[1,2]$. For these events, new transcriptional and translational processes are required for signaling cascades that are generated by the interaction between a receptor (e.g., the toll-like receptor 4 [TLR4]) and a ligand lipopolysaccharide (LPS) [3, 4]. Large numbers of inflammatory signaling enzymes such as nonreceptor protein tyrosine kinases (e.g., Src, Syk, and Janus kinase [JAK]-2), serinethreonine protein kinases (e.g., phosphoinositide 3-kinase [PI3K], phosphoinositide-dependent kinase 1 [PDK1], Akt [protein kinase $\mathrm{B}]$, and inhibitor of $\kappa \mathrm{B} \alpha[\mathrm{I} \kappa \mathrm{B} \alpha]$ kinase [IKK]) activate transcription factors such as nuclear factor (NF) $-\kappa B$ and activator protein (AP)-1 $[5,6]$. In response, numerous inflammatory genes are expressed such as pro-TNF- $\alpha$ for TNF- $\alpha$ secretion, inducible NO synthase (iNOS) for NO release, and cyclooxygenase (COX)-2 for $\mathrm{PGE}_{2}$ production [7-10].

BAY11-7082 (BAY, Figure 1(a)) is a representative IKK inhibitor. Although IKK/NF- $\kappa \mathrm{B}$ is important biochemical factor, the pharmacological activities of BAY such as inhibition of inflammatory cytokines [11], induction of heme oxygenase-1 [12], suppression of ICAM-1 expression [13], reduction of ATPase activity of NLRP3 inflammasome [14], and increase in neutrophil apoptosis [15] strongly indicate that it is not a selective inhibitor of only IKK. Therefore, in this study, we explored its inhibitory potency for inflammatory signals leading to the production of NO, $\mathrm{PGE}_{2}$, and TNF- $\alpha$ under LPS-activated conditions, using primary and cancerous (RAW264.7 cells) macrophages. 


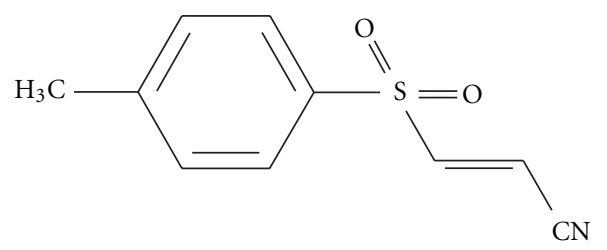

(a)

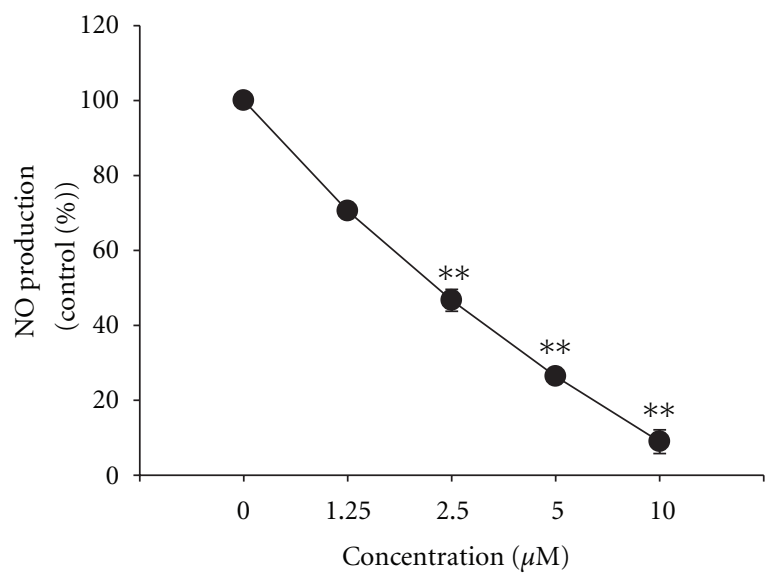

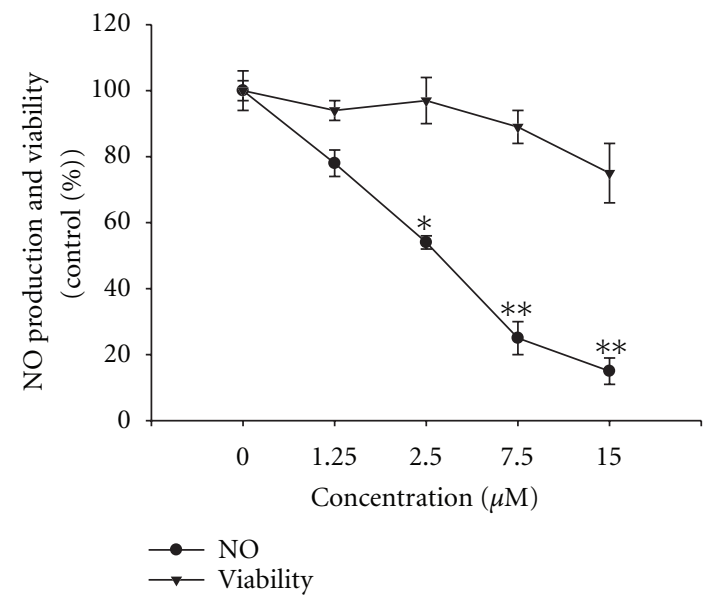

(b)

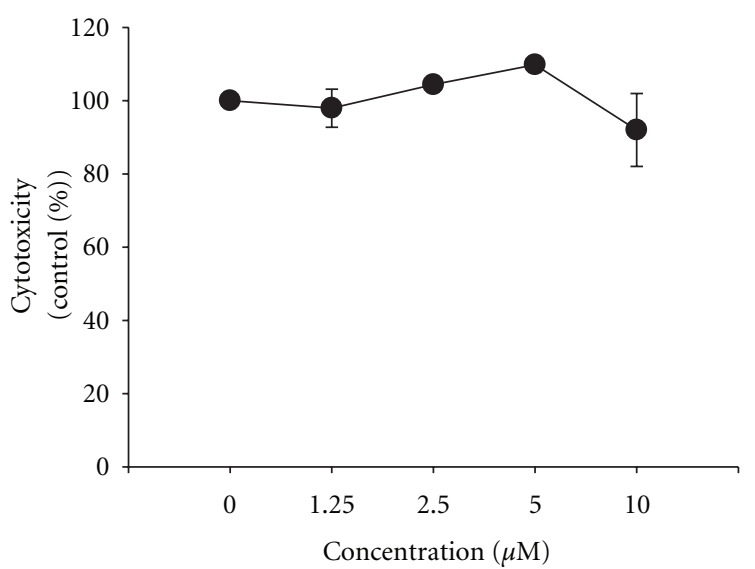

(c)

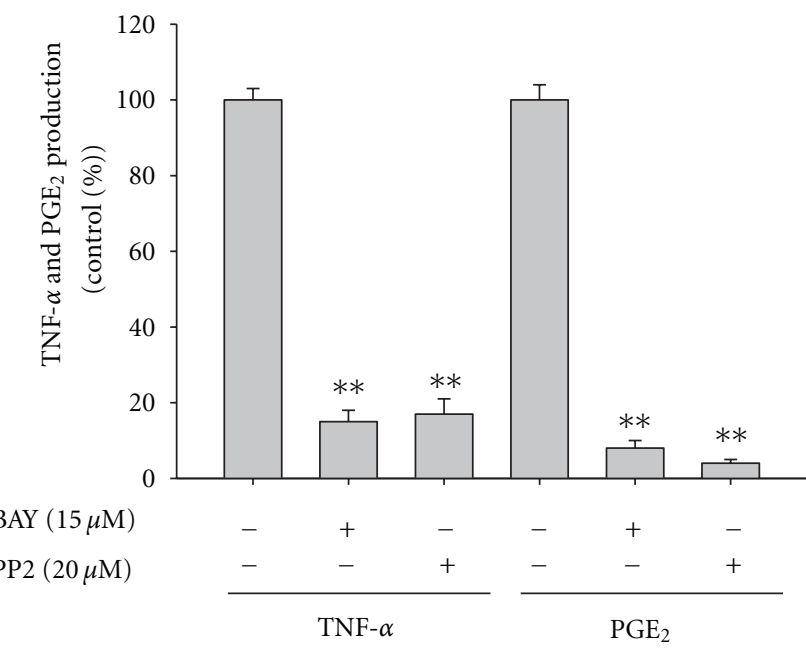

(d)

Figure 1: Effect of BAY (BAY 11-7082) on the production of NO, TNF- $\alpha$, and PGE 2 in RAW264.7 and peritoneal macrophages, and cell viability. (a) Chemical structure of BAY. (b, c left panel, and d) Levels of NO determined by the Griess assay, TNF- $\alpha$ by ELISA, and PGE2 by EIA from culture supernatants of RAW264.7 cell (b and d) and peritoneal macrophages (c) treated with BAY (0 to $15 \mu \mathrm{M})$ in the presence or absence of LPS $(1 \mu \mathrm{g} / \mathrm{mL})$ for $6 \mathrm{~h}(\mathrm{TNF}-\alpha)$ or $24 \mathrm{~h}\left(\mathrm{NO}\right.$ and $\left.\mathrm{PGE}_{2}\right)$. (b and c right panel) Viability of RAW264.7 cells treated with BAY by MTT assays. ${ }^{*} P<0.05$ and ${ }^{* *} P<0.01$ compared to the control. 


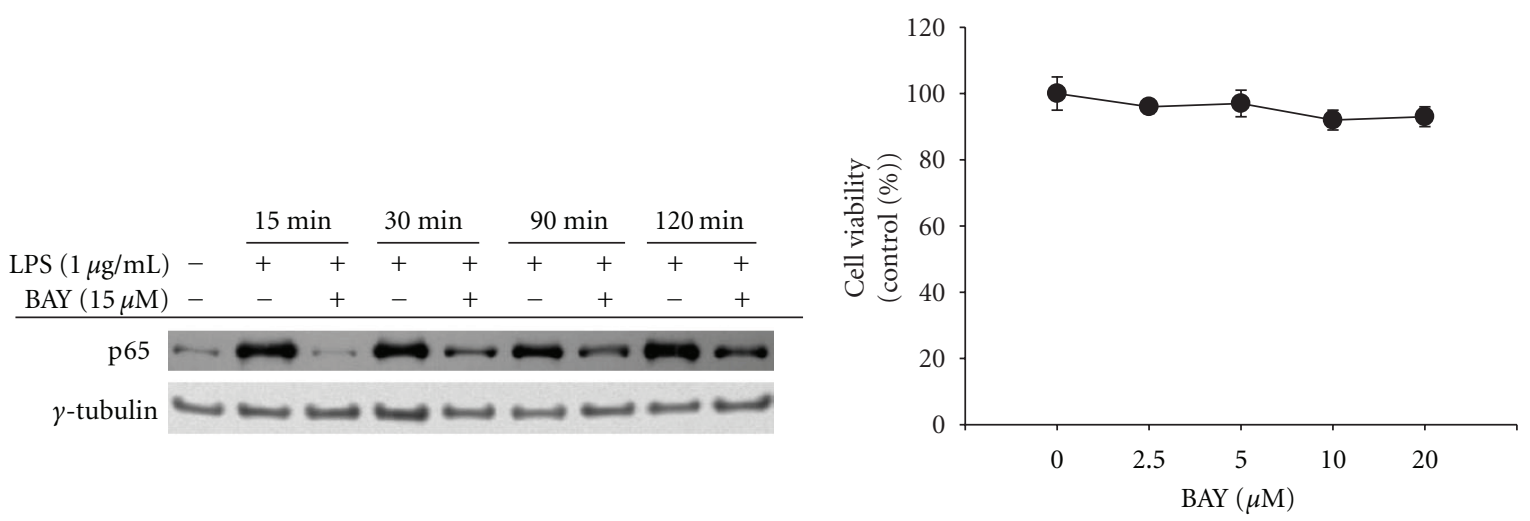

(a)

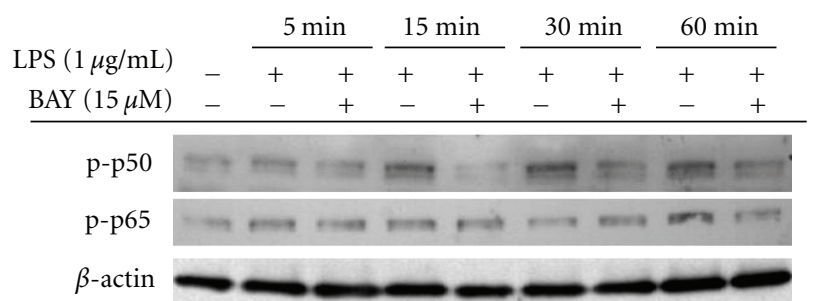

(b)
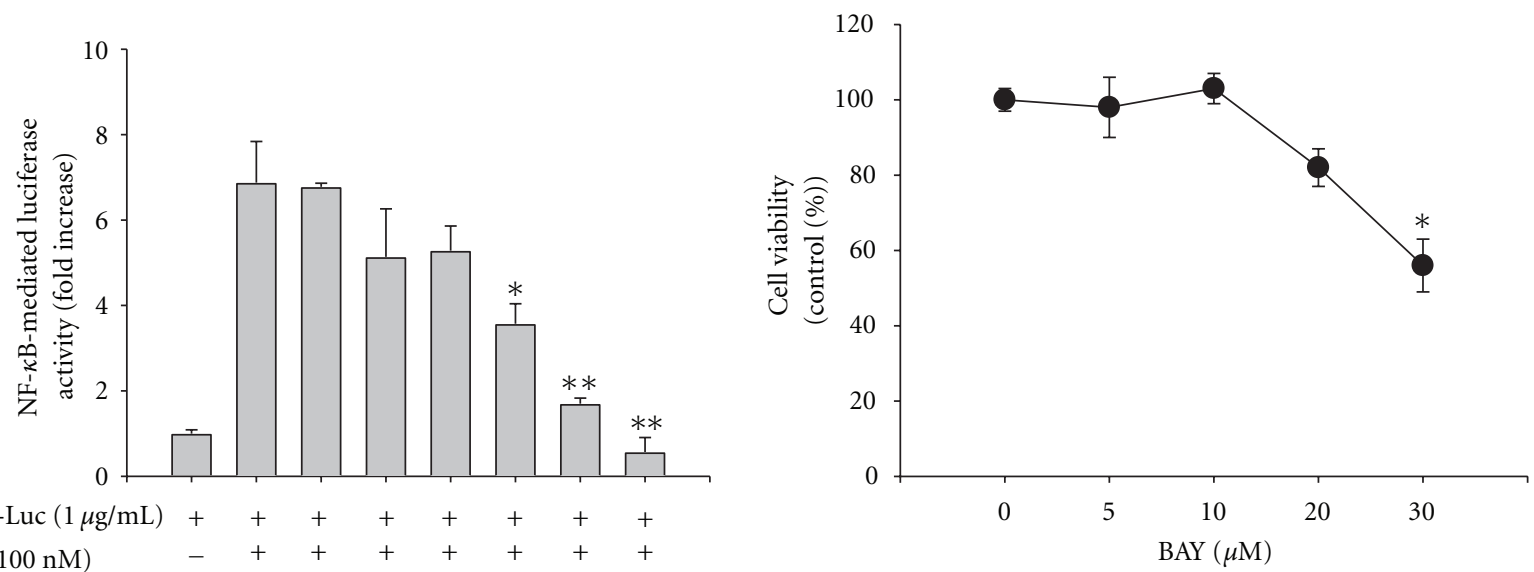

$\begin{array}{lllllllllll}\text { NF- } \kappa \text { B-Luc }(1 \mu \mathrm{g} / \mathrm{mL}) & + & + & + & + & + & + & + & + \\ \text { PMA }(100 \mathrm{nM}) & - & + & + & + & + & + & + & +\end{array}$

$\mathrm{BAY}(\mu \mathrm{M})$

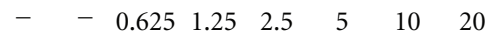

(c)

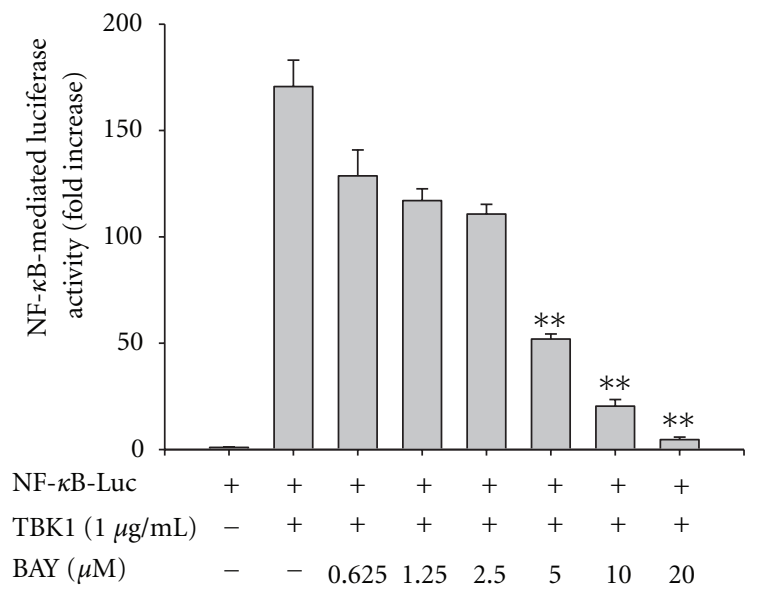

(d)

FIgUre 2: Continued. 


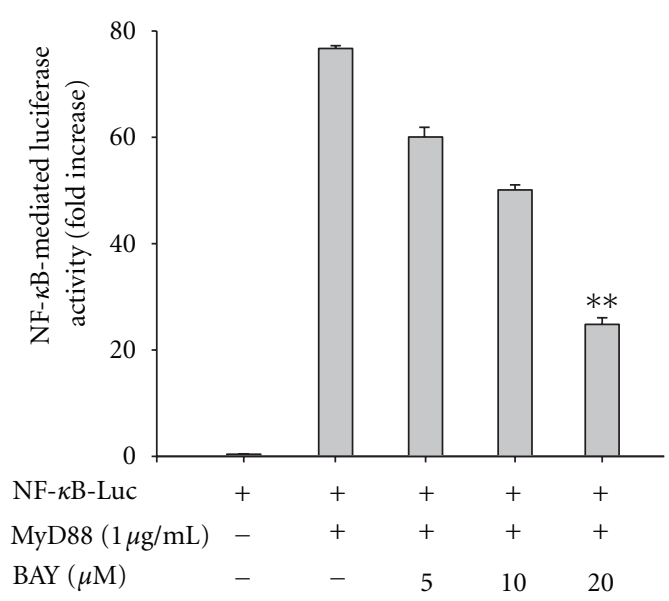

(e)

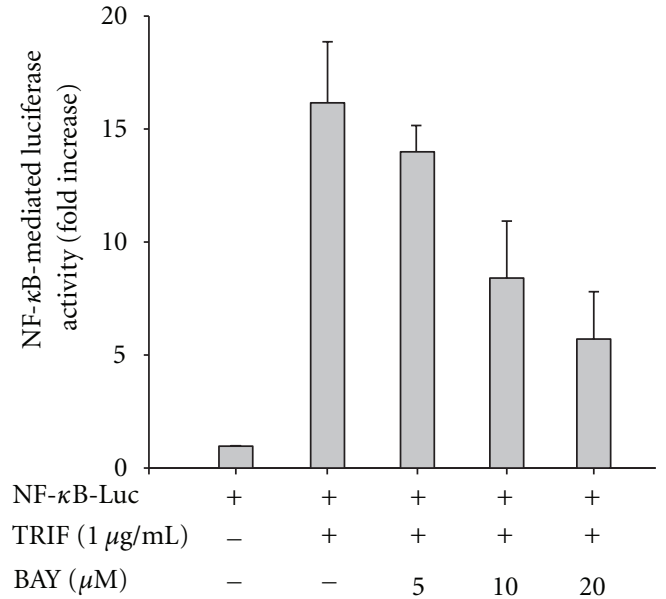

(f)

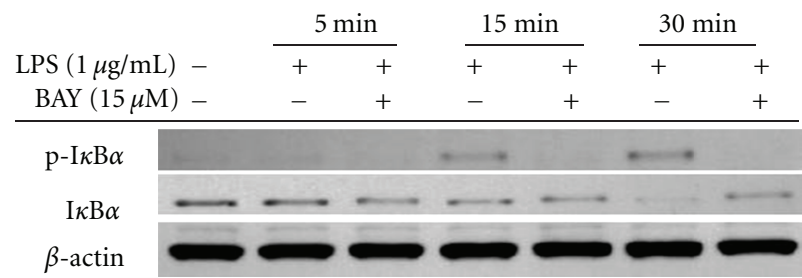

(g)

FIgURE 2: Effect of BAY on transcriptional activation of NF- $\kappa$ B. (a left panel, b, and g) Translocated or phosphorylated levels of NF- $\kappa$ B subunits from nucleus (a) or whole lysates (b) of RAW264.7 cells ( $\mathrm{a}, \mathrm{b}$, and g left panel) or peritoneal macrophages (g right panel) treated with BAY $(15 \mu \mathrm{M})$ in the presence or absence of LPS $(1 \mu \mathrm{g} / \mathrm{mL})$ for indicated times, evaluated by immunoblotting. (c left panel to f) HEK293 cells cotransfected with NF- $\kappa \mathrm{B}$-Luc construct $(1 \mu \mathrm{g} / \mathrm{mL})$ and $\beta$-gal (transfection control) were treated with BAY $(0$ to $20 \mu \mathrm{M})$ in the presence or absence of PMA $(100 \mathrm{nM})$ or by cotransfection with NF- $\kappa$ B activation inducers (MyD88, TRIF, and TBK1). Luciferase activity was measured using a luminometer. (a right panel and c right panel) Viability of RAW264.7 (a right panel) and HEK293 (c right panel) cells treated with BAY $\left(0\right.$ to 20 or $30 \mu \mathrm{M}$ ) for 2 or $24 \mathrm{~h}$ was examined by MTT assays. ${ }^{*} P<0.05$ and ${ }^{* *} P<0.01$ compared to the control.

\section{Materials and Methods}

2.1. Materials. BAY 11-7082, or (E)-3-(4-methylphenylsulfonyl)-2-propenenitrile; lipopolysaccharide (LPS; Escherichia coli 0111:B4); and 3-4,5-(dimethylthiazol-2-yl)-2,5diphenyltetrazolium bromide (MTT) were from Sigma Chemical Co. (St. Louis, MO, USA). LY294002, wortmannin, U0126 (U0), SB203580 (SB), SP600125 (SP), and PP2 were from Calbiochem (La Jolla, CA, USA). Luciferase constructs containing promoters sensitive to NF- $\kappa \mathrm{B}, \mathrm{CREB}$, and $\mathrm{AP}-1$ were gifts from Profs. Hae Young Chung (Pusan National University, Pusan, Korea) and Man Hee Rhee (Kyungpook National University, Daegu, Korea). Enzyme immunoassay (EIA) kits and enzyme-linked immunosorbent assay (ELISA) kits for determining $\mathrm{PGE}_{2}$ and TNF- $\alpha$ were from Amersham (Little Chalfont, Buckinghamshire, UK). Fetal bovine serum and RPMI1640 were from Gibco (Grand Island, NY, USA). The murine macrophage cell line RAW264.7 and the human embryonic kidney cell line HEK293 were from the ATCC (Rockville, MD, USA). All other chemicals were of analytical grade and from Sigma. Phosphospecific or total antibodies to p65, p50, Src, Syk, PDK1, p85, Akt, I $\kappa \mathrm{B} \alpha, \mathrm{p} 38, \mathrm{ERK}, \mathrm{JNK}$, lamin $\mathrm{A} / \mathrm{C}$, and $\beta$ actin were from cell signaling (Beverly, MA, USA).
2.2. Mice. Six-week-old male C57BL/6 and ICR mice were from DAEHAN BIOLINK (Chungbuk, Korea). Mice were given food pellets (Samyang, Daejeon, Korea) and water ad libitum under a 12-h light/dark cycle. Studies were performed in accordance with guidelines established by the Kangwon National University Institutional Animal Care and Use Committee.

2.3. Preparation of Peritoneal Macrophages. Peritoneal exudates were obtained from male C57BL/6 mice (7-8 weeks old, $17-21 \mathrm{~g}$ ) by lavaging 4 days after intraperitoneal injection of $1 \mathrm{~mL}$ of sterile $4 \%$ thioglycollate broth (Difco Laboratories, Detroit, MI), as reported previously [16]. After washing with RPMI 1640 medium containing 2\% fetal bovine serum (FBS), peritoneal macrophages $\left(1 \times 10^{6}\right.$ cells $\left./ \mathrm{mL}\right)$ were plated in $100 \mathrm{~mm}$ tissue culture dishes for $4 \mathrm{~h}$ at $37^{\circ} \mathrm{C}$ in a $5 \% \mathrm{CO}_{2}-$ humidified atmosphere.

2.4. Cell Culture. RAW264.7 and HEK293 cells were cultured in DMEM or RPMI1640 medium supplemented with 10\% heat-inactivated FBS (Gibco, Grand Island, NY, USA), glutamine, and antibiotics (penicillin and streptomycin) at $37^{\circ} \mathrm{C}$ under $5 \% \mathrm{CO}_{2}$. Cells were detached with a cell scraper. At the cell density used for the experiments $\left(2 \times 10^{6}\right.$ cells $\left./ \mathrm{mL}\right)$, 
the proportion of dead cells was less than $1 \%$ as measured by trypan blue dye exclusion.

2.5. Determination of $N O, P G E_{2}$, and $T N F-\alpha$. After preincubation of RAW264.7 cells $\left(1 \times 10^{6}\right.$ cells $\left./ \mathrm{mL}\right)$ or bone marrowderived macrophages $\left(2 \times 10^{6}\right.$ cells $\left./ \mathrm{mL}\right)$ for $18 \mathrm{~h}$, cells were pretreated with BAY ( 0 to $15 \mu \mathrm{M})$ for $30 \mathrm{~min}$ and further incubated with LPS $(1 \mu \mathrm{g} / \mathrm{mL})$ for 6 (TNF- $\alpha)$ or 24 (NO and $\left.\mathrm{PGE}_{2}\right)$ h. Levels of NO, PGE 2 , and TNF- $\alpha$ were determined with Griess reagent and ELISA kits as described previously $[17,18]$.

2.6. Cell Viability Test. After preincubation of RAW264.7 or HEK293 cells $\left(2.5 \times 10^{6}\right.$ cells $\left./ \mathrm{mL}\right)$ for $18 \mathrm{~h}$, BAY (0 to 15 or $30 \mu \mathrm{M})$ was added to the cells and incubated for 2 or $24 \mathrm{~h}$. The cytotoxic effect of BAY was evaluated by a conventional MTT assay, as reported previously [19, 20]. At 1 or $3 \mathrm{~h}$ before culture termination, $10 \mu \mathrm{L}$ MTT solution ( $10 \mathrm{mg} / \mathrm{mL}$ in phosphate-buffered saline, $\mathrm{pH}$ 7.4) was added to each well, and the cells were continuously cultured until termination of the experiment. Incubation was halted by the addition of $15 \%$ sodium dodecyl sulfate (SDS) into each well, solubilizing the formazan [21]. Absorbance at $570 \mathrm{~nm}\left(\mathrm{OD}_{570-630}\right)$ was measured using a SpectraMax 250 microplate reader.

2.7. Preparation of Cell Lysates and Nuclear Fraction, and Immunoblotting. RAW264.7 cells $\left(5 \times 10^{6}\right.$ cells/mL) were washed three times in cold PBS with $1 \mathrm{mM}$ sodium orthovanadate and lysed by a sonicator in lysis buffer $(20 \mathrm{mM}$ tris$\mathrm{HCl}, \mathrm{pH}$ 7.4, $2 \mathrm{mM}$ EDTA, $2 \mathrm{mM}$ ethyleneglycotetraacetic acid, $50 \mathrm{mM} \beta$-glycerophosphate, $1 \mathrm{mM}$ sodium orthovanadate, $1 \mathrm{mM}$ dithiothreitol, $1 \%$ Triton X-100, 10\% glycerol, $10 \mu \mathrm{g} / \mathrm{mL}$ aprotinin, $10 \mu \mathrm{g} / \mathrm{mL}$ pepstatin, $1 \mathrm{mM}$ benzimide, and $2 \mathrm{mM}$ PMSF) for $30 \mathrm{~min}$ with rotation at $4^{\circ} \mathrm{C}$. Lysates were clarified by centrifugation at $16,000 \mathrm{xg}$ for $10 \mathrm{~min}$ at $4^{\circ} \mathrm{C}$ and stored at $-20^{\circ} \mathrm{C}$ until needed.

Nuclear lysates were prepared in a three-step procedure [22]. After treatment, cells were collected with a rubber policeman, washed with $\mathrm{PBS}$, and lysed in $500 \mu \mathrm{L}$ lysis buffer containing $50 \mathrm{mM} \mathrm{KCl}, 0.5 \%$ Nonidet P-40, $25 \mathrm{mM}$ HEPES ( $\mathrm{pH}$ 7.8), $1 \mathrm{mM}$ phenylmethylsulfonyl fluoride, $10 \mu \mathrm{g} / \mathrm{mL}$ leupeptin, $20 \mu \mathrm{g} / \mathrm{mL}$ aprotinin, and $100 \mu \mathrm{M} \mathrm{1,4-}$ dithiothreitol (DTT) on ice for $4 \mathrm{~min}$. Cell lysates were centrifuged at 19,326 xg for $1 \mathrm{~min}$ in a microcentrifuge. In the second step, the nuclear fraction pellet was washed once in washing buffer (lysis buffer without Nonidet P-40). In the final step, nuclei were treated with an extraction buffer of lysis buffer with $500 \mathrm{mM} \mathrm{KCl}$ and $10 \%$ glycerol. The nuclei/ extraction buffer mixture was frozen at $-80^{\circ} \mathrm{C}$, thawed on ice and centrifuged at $19,326 \mathrm{xg}$ for $5 \mathrm{~min}$. The supernatant was collected as a nuclear extract. Soluble cell lysates were immunoblotted and protein levels determined as previously reported [23].

2.8. Luciferase Reporter Gene Activity Assay. HEK293 cells $\left(1 \times 10^{6}\right.$ cells $\left./ \mathrm{mL}\right)$ were transfected with $1 \mu \mathrm{g}$ of plasmid containing NF- $\kappa$ B-Luc, IFN- $\beta$-promoter-Luc, CREB-Luc, or AP1 -Luc as well as $\beta$-galactosidase using the polyethylenimine
TABLE 1: Real-time PCR primers.

\begin{tabular}{lcc}
\hline Name & & Sequence $\left(5^{\prime}\right.$ to $\left.3^{\prime}\right)$ \\
\hline \multirow{2}{*}{ iNOS } & F & GGA GCC TTT AGA CCT CAA CAG A \\
& R & TGA ACG AGG AGG GTG GTG \\
COX-2 & F & CACTACATCCTGACCCACTT \\
& R & ATGCTCCTGCTTGAGTATGT \\
GAPDH & F & CAA TGA ATA CGG CTA CAG CAA C \\
& R & AGG GAG ATG CTC AGT GTT GG \\
\hline
\end{tabular}

(PEI) method in a 12-well plate according to a previous report [24]. Cells were used $48 \mathrm{~h}$ after transfection. Luciferase assays were performed using the Luciferase Assay System (Promega) as reported previously [25].

2.9. mRNA Analysis by SemiQuantitative Reverse Transcriptase- and Real-Time Polymerase Chain Reactions. To determine cytokine mRNA expression levels, total RNA was isolated from LPS-treated RAW264.7 cells with TRIzol Reagent (Gibco), according to the manufacturer's instructions. Total RNA was stored at $-70^{\circ} \mathrm{C}$ until use. Semiquantitative reverse transcriptase (RT) reactions were conducted as reported previously $[26,27]$. Quantification of mRNA was performed using real-time RT-PCR according to the manufacturer's instructions for SYBR Premix Ex Taq (Takara Bio, Inc., Shiga, Japan) using a real-time thermal cycler (Bio-Rad, Hercules, CA, USA) as reported previously [28]. Results were expressed as optimal density ratios to GAPDH. Primers (Bioneer, Daejeon, Korea) are in Table 1.

2.10. Statistical Analysis. Data (Figures 1(b)-1(d), 2(c)-2(f), 4(b)-4(e), 4(g), 5(a), 5(b), and 5(e)) are expressed as the mean with standard deviation (SD) as calculated from one $(n=6)$ of two independent experiments. Other data are representative of three different experiments with similar results. For statistical comparisons, results were analyzed using Mann-Whitney test. All $P$ values $<0.05$ were considered statistically significant. All statistical tests were conducted using SPSS (SPSS Inc., Chicago, IL, USA).

\section{Results and Discussion}

As previously reported, BAY showed strong inhibition of NF- $\kappa \mathrm{B}$ activation. BAY blocked the production of $\mathrm{NO}$, $\mathrm{PGE}_{2}$, and TNF- $\alpha$, well-known inflammatory responses generated by activated NF- $\kappa$ B [29], in LPS-treated RAW264.7 cells (Figures 1(b) and 1(d)) and peritoneal macrophages (Figure 1(c)). It suppressed the translocation of NF- $\kappa \mathrm{B}$ subunit (p65) in a time-dependent manner (Figure 2(a) left panel) and blocked the phosphorylation of p50 and p65 in whole cell lysates (Figure 2(b)), without altering cell viability up to $20 \mu \mathrm{M}$ (Figure 2 (a) right panel), indicating that it could specifically block the activation and translocation pathway of NF- $\kappa \mathrm{B}$ as reported previously [30]. As shown in Figures $2(\mathrm{c})-2(\mathrm{f})$, BAY (0 to $20 \mu \mathrm{M})$ diminished the activity of NF- $\kappa \mathrm{B}$ induced by PMA, a cell permeable PKC activator, and adaptor or signaling molecules of TLR 


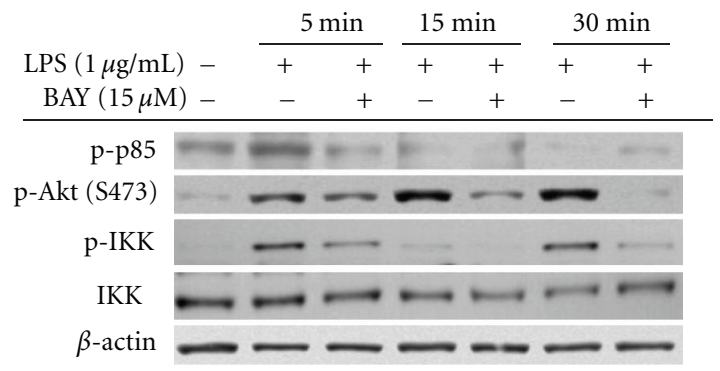

(a)

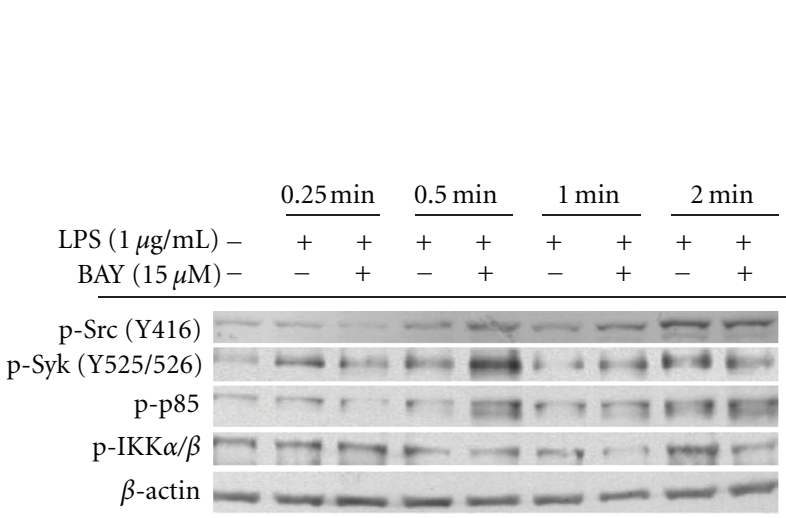

(b)
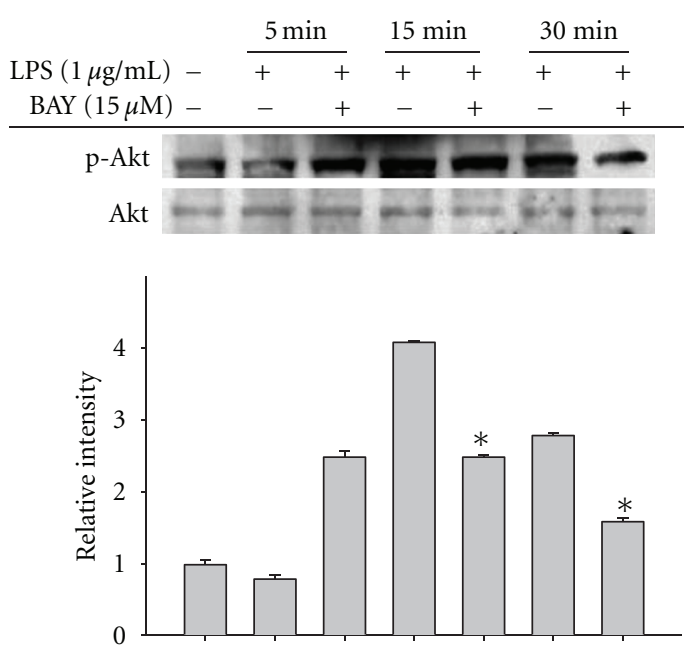

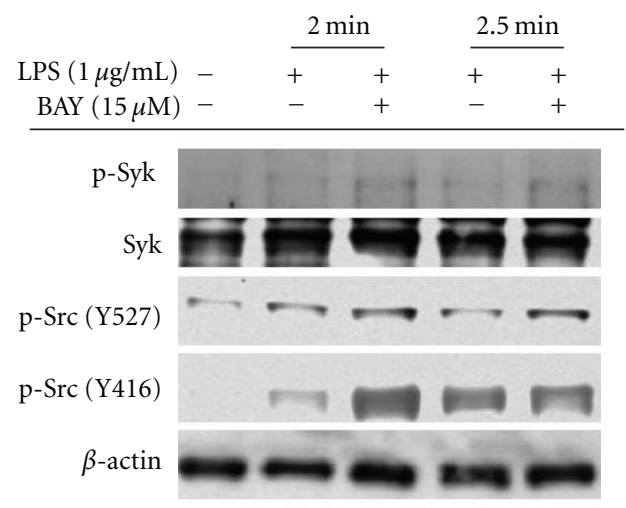

(c)

Figure 3: Effect of BAY on the activation of upstream signaling for NF- $\kappa$ B translocation. (a to c) RAW264.7 cells (a left panel, b, and c) or peritoneal macrophages (a right panel) $\left(5 \times 10^{6}\right.$ cells $\left./ \mathrm{mL}\right)$ were incubated with BAY $(15 \mu \mathrm{M})$ in the presence or absence of LPS $(1 \mu \mathrm{g} / \mathrm{mL})$ for indicated times. After preparing whole lysates, levels of phospho (p)- or total proteins of I $\kappa \mathrm{B} \alpha, \mathrm{IKK} \alpha / \beta, \mathrm{Akt}, \mathrm{p} 85 / \mathrm{PI} 3 \mathrm{~K}$, Syk, and Src were identified by immunoprecipitation. Relative intensity (a right panel) was calculated by densitometric scanning.

(TRIF, MyD88, and TBK1), as assessed by reporter gene assay. Furthermore, $\mathrm{I} \kappa \mathrm{B} \alpha$ phosphorylation [31], a representative upstream pathway for NF- $\kappa \mathrm{B}$ translocation, was also strongly suppressed in LPS-treated RAW264.7 cells (Figure 2(g) left panel) and peritoneal macrophages (Figure 2(g) right panel), as reported previously [32], due to its direct inhibition of IKK [33].

Unexpectedly, however, the pharmacological activity of BAY seemed not to be limited to IKK inhibition. It clearly suppressed IKK phosphorylation (Figure 3(a) left panel), mediated by Akt in inflammatory signaling. Furthermore, it blocked the phosphorylation of Akt in both LPS-treated RAW264.7 cells (Figure 3(a) right panel) and peritoneal macrophages (Figure 3(a) right panel), indicating that the target of BAY in inflammatory signaling was upstream of IKK and Akt. Since Src and Syk are representative upstream kinases that activate PI3K, PDK1, and Akt by cascade phosphorylation [34], we evaluated whether these enzymes were suppressed by BAY. As shown in Figures 3(b) and $3(c)$, BAY did not suppress the phosphorylation of $\mathrm{p} 85$, a regulatory subunit of PI3K [35], or its upstream kinases Syk and Src, but diminished p-IKK levels at $2 \mathrm{~min}$. This suggested that the target of BAY in the NF- $\kappa \mathrm{B}$ inhibitory pathway was not IKK, but a protein activated upstream of IKK and downstream of Src and Syk. Currently, we do not know which enzyme directly contributes to inhibition by BAY. One of three PI3K isoforms or PDK1 could be the actual target that is regulated by BAY. We plan to conduct future experiments to determine this.

In addition to NF- $\kappa \mathrm{B}, \mathrm{AP}-1$ is a representative transcription factor that is activated in inflammatory responses [36]. Therefore, we examined whether BAY blocked the activation of AP-1 in LPS-treated RAW264.7 cells, by measuring the nuclear translocated level of AP-1 components, c-Jun and cFos, and using a reporter gene (luciferase) assay with DNA construct containing an AP-1-binding promoter region. As seen in Figures 4(a)-4(d), BAY suppressed the promoterbinding activity of AP-1 induced by PMA and TBK1, but not TRIF and MyD88, as assessed by luciferase activity. Similarly, BAY also strongly suppressed nuclear translocation of c-Fos 


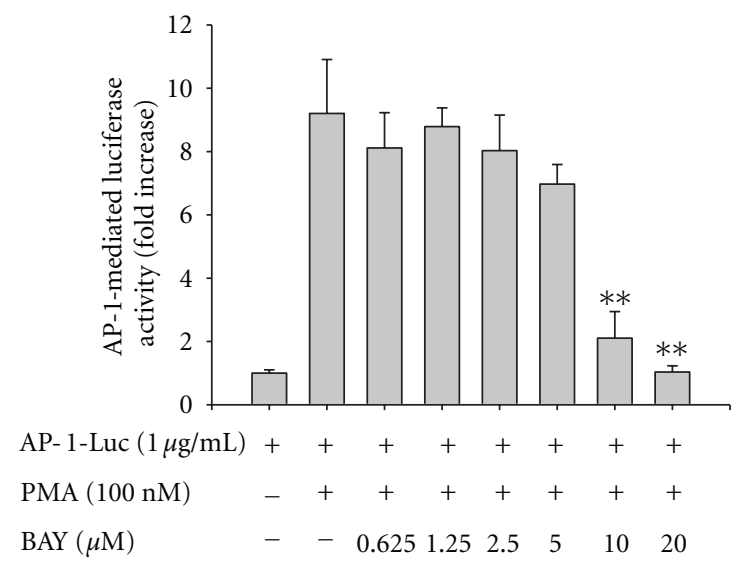

(a)

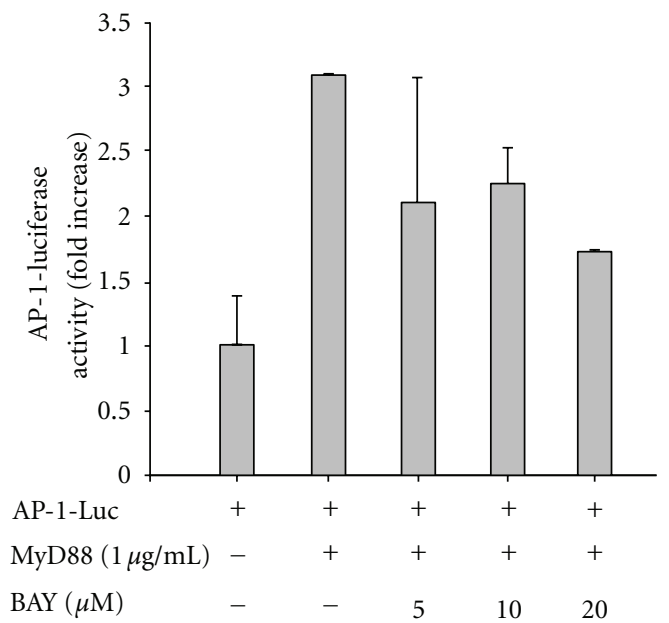

(c)

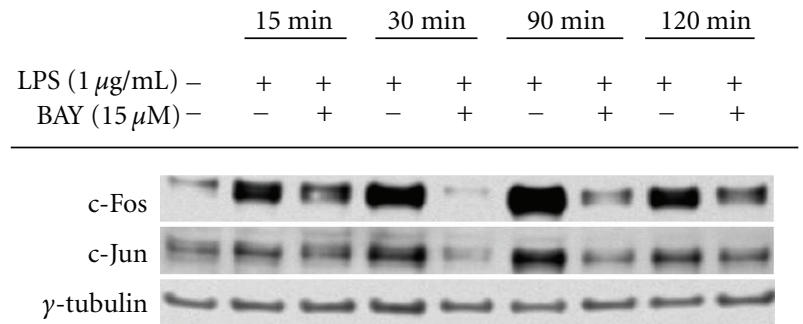

(e)

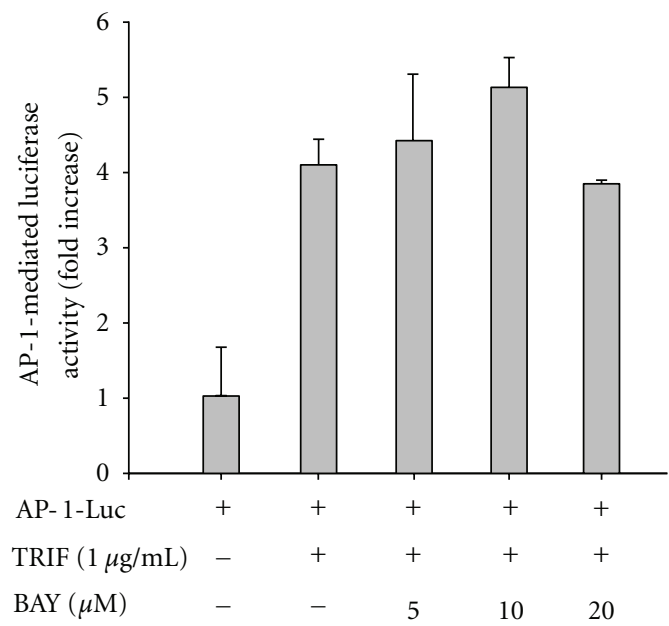

(b)

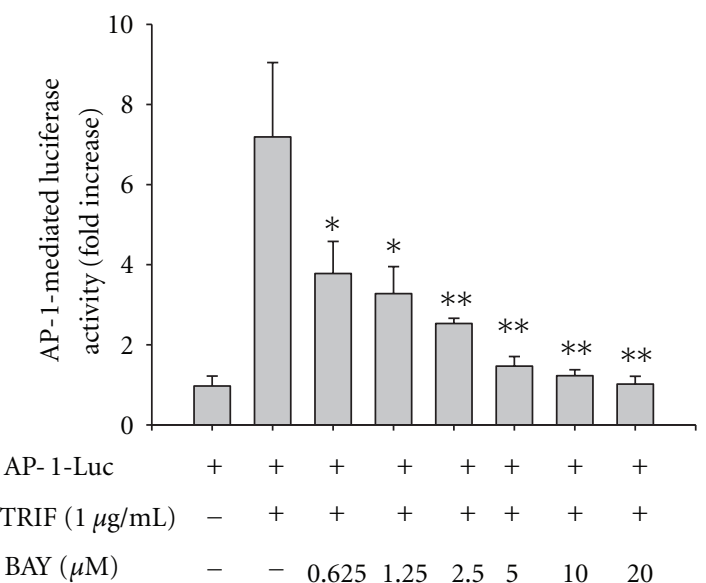

(d)

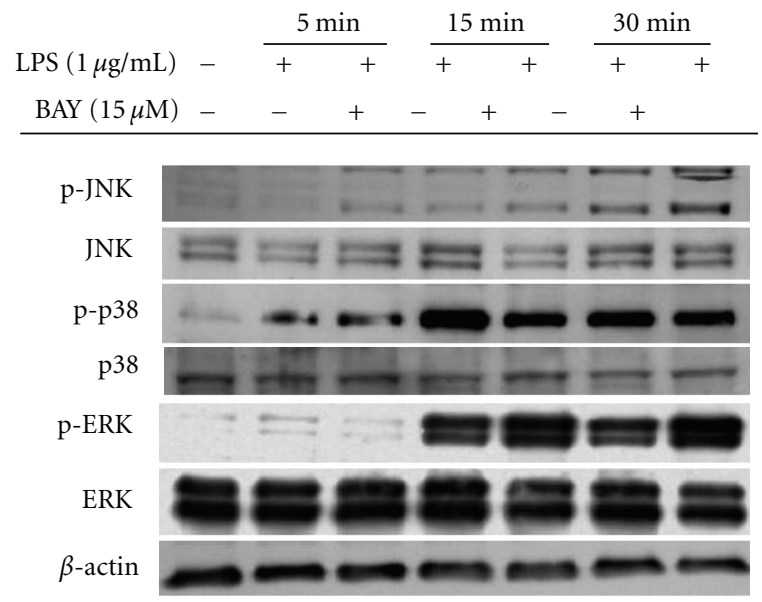

(f)

FIgURE 4: Continued. 


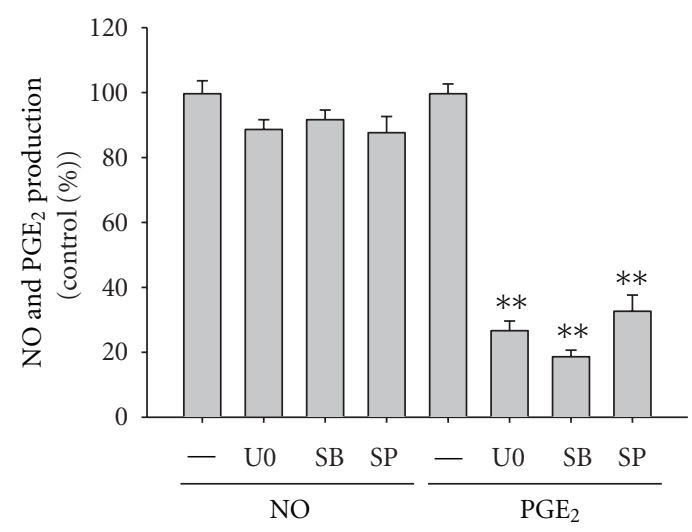

(g)

FIGURE 4: Effect of BAY on the activation of the AP-1 pathway. (a to d) HEK293 cells cotransfected with AP-1-Luc construct ( $1 \mu \mathrm{g} / \mathrm{mL}$ ) and $\beta$ gal (as a transfection control) were treated with BAY $(0$ to $20 \mu \mathrm{M})$ in the presence or absence of PMA (100 nM) or by cotransfection with AP-1 activation inducers (MyD88, TRIF, and TBK1). Luciferase activity was measured using a luminometer. (e) Translocated or phosphorylated levels of AP-1 family (c-Fos and c-Jun) from the nucleus from RAW264.7 cells treated with BAY (15 $\mu \mathrm{M})$ in the presence or absence of LPS $(1 \mu \mathrm{g} / \mathrm{mL})$, evaluated by immunoblotting. (f) RAW264.7 cells $\left(5 \times 10^{6}\right.$ cells $\left./ \mathrm{mL}\right)$ were incubated with BAY $(15 \mu \mathrm{M})$ in the presence or absence of LPS $(1 \mu \mathrm{g} / \mathrm{mL})$ for indicated times. After preparing total lysates, levels of phospho (p)- or total proteins of JNK, p38, and ERK were identified by immunoprecipitation. (g) Levels of NO determined by the Griess assay and PGE2 by EIA from culture supernatants of RAW264.7 cell treated with U0126 (U0), SB203580 (SB), or SP600125 (SP) in the presence or absence of LPS $(1 \mu \mathrm{g} / \mathrm{mL})$ for $24 \mathrm{~h} .{ }^{*} P<0.05$ and ${ }^{* *} P<0.01$ compared to the control.

and c-Jun (Figure 4(e)), indicating that it could modulate the activation pathway required for the translocation of AP1. Indeed, BAY reduced important upstream events for AP-1 translocation. Thus, it diminished the phosphorylation levels of ERK at $5 \mathrm{~min}$ and p38 at $15 \mathrm{~min}$ although it also increased the phosphorylation of ERK at 15 to 30 min (Figure 4(f)). Therefore, our data suggested that BAY had a negative effect on AP-1 activation pathway, managed by PKC and TBK1, via indirectly suppressing MAPK (ERK and p38) activation pathway. The fact that U0126 (U0), an ERK inhibitor, and SB203580 (SB), a p38 inhibitor, blocked the production of $\mathrm{PGE}_{2}$ and TNF- $\alpha$ (data not shown), but not NO (Figure $4(\mathrm{~g})$ ), implies that BAY-mediated inhibition of ERK and $\mathrm{p} 38$ phosphorylation did not affect its NO inhibitory action.

Recent work on inflammatory signaling demonstrated a critical role for IRF-3 in releasing type I interferons such as IFN- $\alpha$ and IFN- $\beta$ [37], and additional inflammatory responses by these cytokines via activation of the JAK2/STAT1 pathway [38]. The activation of the JAK2/STAT-1 pathway is important in the expression of iNOS and COX-2 and other proinflammatory cytokines such as IL- $1 \beta$ and TNF- $\alpha$ [39]. Blockade of the IRF-3 pathway with BX795, a TBK1 inhibitor [40], blocked the expression of iNOS and COX-2 and suppressed the production of $\mathrm{NO}$ and $\mathrm{PGE}_{2}$ (Figure 5(a)). AG490, an inhibitor of JAK2/STAT-1 pathway also elicited strong anti-inflammatory responses (Figure 5(b)). Therefore, we examined whether these pathways were also targeted by BAY. BAY strongly suppressed the translocation of IRF3 into the nucleus (Figure 5(c)) and its phosphorylation in the cytosol (Figure 5(d)). This indicated that the IRF-3 regulatory pathway was also directly modulated by BAY. In agreement, BAY diminished the upregulation of luciferase activity induced by TBK1 (Figure 5(e)), suggesting that the TBK1-mediated inflammatory pathway was a BAY target. Suppression of the JAK2/STAT-1 pathway by BAY was determined by measuring the nuclear translocation of phospho-STAT-1 and its upstream kinase. This also strongly indicated involvement in BAY-mediated inhibition. BAY strongly suppressed the phosphorylation of STAT-1 at $120 \mathrm{~min}$ in the nucleus (Figure 5(f)) and JAK-2 at 0.25 and $2 \mathrm{~min}$ in whole cell lysates (Figure $5(\mathrm{~g})$ ), suggesting that the JAK-2/STAT-1-mediated inflammatory responses were also targeted by BAY.

The mechanism of broad-spectrum pharmacological activity of BAY in various inflammatory signaling pathways is not clear. The main factor of this could be derived by its structural properties. Several compounds (e.g., celecoxib, phenylpropanoid derivatives) with a methylphenyl group in their backbone display anti-inflammatory activity by inhibiting various enzyme targets [41, 42]. Recently, we have also found that 8-(tosylamino)quinoline (8-TQ), with a similar structural backbone, strongly suppresses various inflammatory signaling cascades (Jung et al., submitted). Therefore, our data suggested that a structural feature of BAY contributed to its multiple pharmacological activities. Since a compound, 3-(4-(tert-octyl)phenoxy)propane-1,2diol, with multiple inhibitory targets such as Syk, IKK, and p38, was found to display higher in vivo efficacy [43], it seems to be worth to further develop BAY derivatives. In view of this, we are currently collaborating with several Chemists to synthesize and develop pharmacologically stronger BAY derivatives.

In summary, BAY exhibited broad-spectrum inhibitory activity against inflammatory signaling pathways including PI3K/Akt/IKK/NF- $\kappa$ B, ERK/JNK/AP-1, TBK1/IRF-3, and 

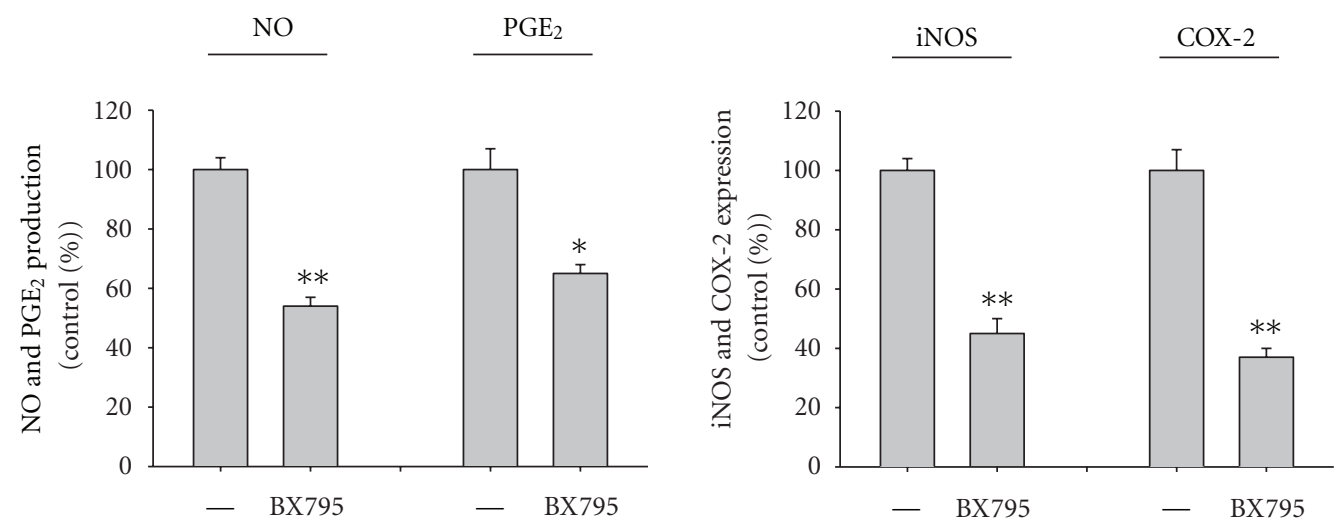

(a)

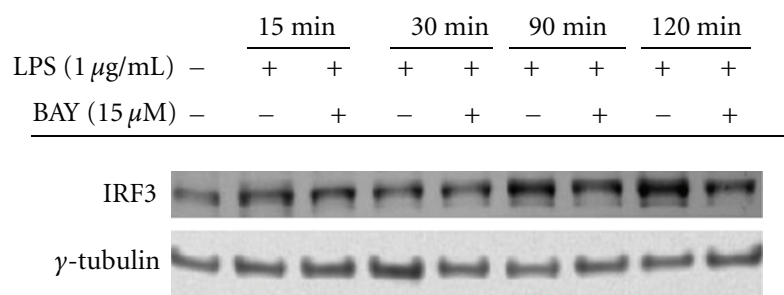

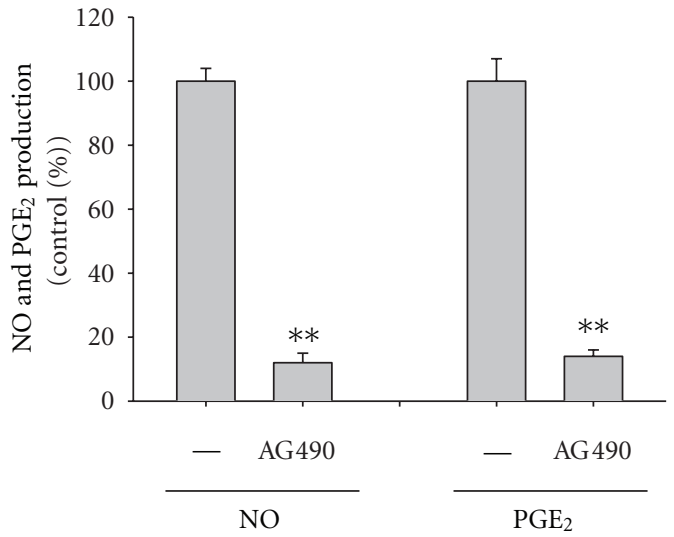

(b)

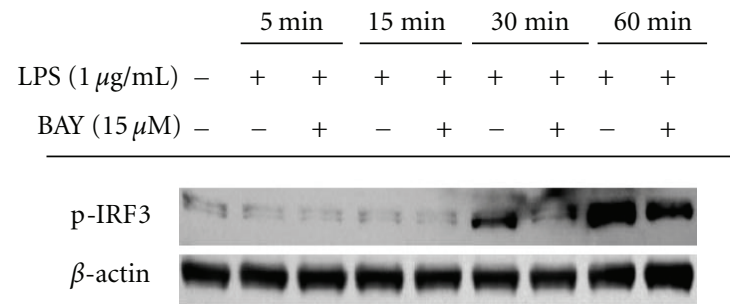

(d)

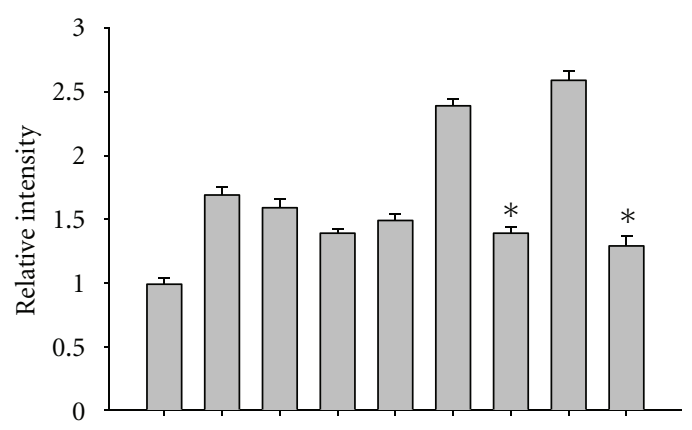

(c)

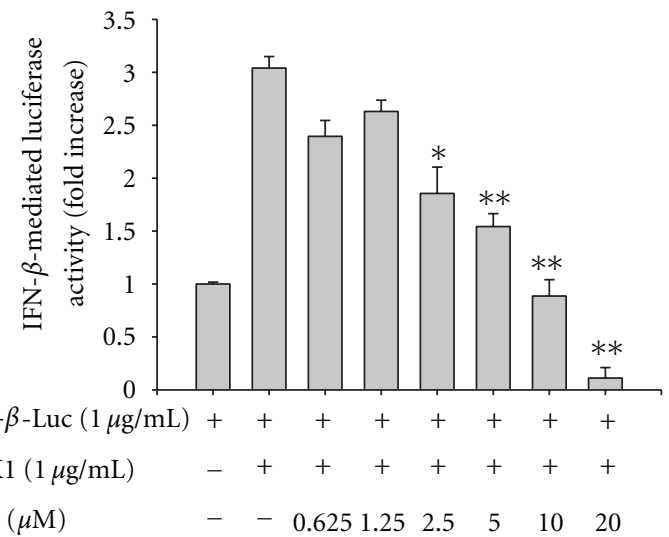

(e)

Figure 5: Continued. 

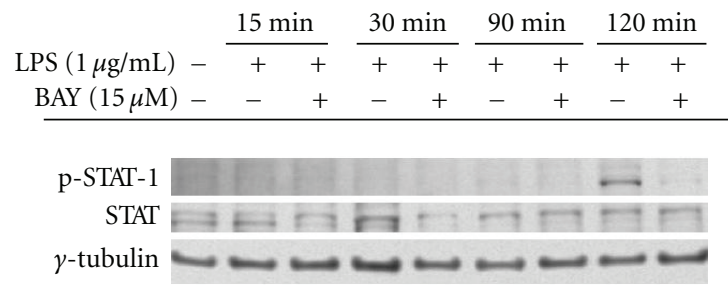

(f)
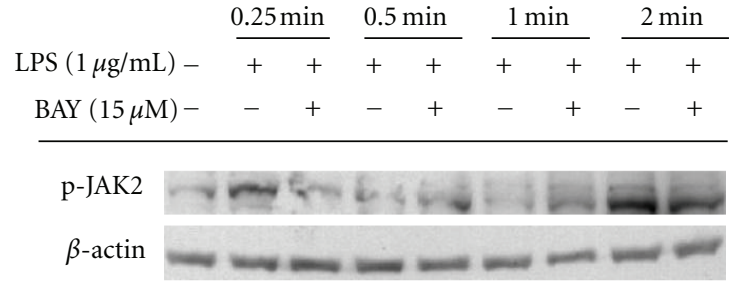

(g)

FIGURE 5: Effect of BAY on the activation of the IRF-3 pathway. (a left panel and b) Levels of NO by the Griess assay and PGE 2 by EIA from culture supernatants of RAW264.7 cell treated with BX795 $(5 \mu \mathrm{M})$ or AG490 $(20 \mu \mathrm{M})$ in the presence or absence of LPS $(1 \mu \mathrm{g} / \mathrm{mL})$ for $24 \mathrm{~h}$. (a right panel) Levels of COX-2 and iNOS mRNA by real-time PCR using LPS-treated RAW274.7 cells pretreated with BX795 (5 $\mu \mathrm{M})$ for $6 \mathrm{~h}$. (c, d, f, and g) Translocated or phosphorylated levels of IRF-3, STAT-1 or JAK2 from nucleus (c and f) or total lysates ( $\mathrm{d}$ and g) from RAW264.7 cells treated with BAY $(15 \mu \mathrm{M})$ in the presence or absence of LPS $(1 \mu \mathrm{g} / \mathrm{mL})$ for indicated times, evaluated by immunoblotting. (e) HEK293 cells cotransfected with IFN- $\beta$-promoter-1-Luc construct $(1 \mu \mathrm{g} / \mathrm{mL})$ and $\beta$-gal (as a transfection control) were treated with BAY in the presence or absence of TBK1 $(1 \mu \mathrm{g} / \mathrm{mL})$. Luciferase activity was measured using a luminometer. Relative intensity (c) was calculated by densitometric scanning. ${ }^{*} P<0.05$ and ${ }^{* *} P<0.01$ compared to the control.

JAK-2/STAT-1. The suppressive activity of BAY was linked to the suppression of NO, TNF- $\alpha$, and $\mathrm{PGE}_{2}$ release. Although the direct target of BAY needs to be identified, our data strongly implied that BAY inhibited the TLR4-activated signaling cascade and the subsequent inflammatory response by targeting multiple signaling enzymes and transcription factors. Considering that inflammatory responses occurred through multiple signaling pathways, and simultaneous inhibition of these pathways contributes to maximum therapeutic potential, the chemical optimization of BAY could be helpful in developing strong BAY-derived anti-inflammatory drugs with multiple targets.

\section{Acknowledgment}

This research was supported by a grant from Sungkyunkwan University (2011).

\section{References}

[1] I. T. Harvima and G. Nilsson, "Mast cells as regulators of skin inflammation and immunity," Acta Dermato-Venereologica, vol. 91, no. 6, pp. 644-650, 2011.

[2] R. J. Toncic, J. Lipozencic, I. Martinac, and S. Greguric, "Immunology of allergic contact dermatitis," Acta Dermatovenerologica Croatica, vol. 19, no. 1, pp. 51-68, 2011.

[3] R. W. Kinne, R. Bräuer, B. Stuhlmüller, E. Palombo-Kinne, and G. R. Burmester, "Macrophages in rheumatoid arthritis," Arthritis Research, vol. 2, no. 3, pp. 189-202, 2000.

[4] T. Owens, A. A. Babcock, J. M. Millward, and H. Toft-Hansen, "Cytokine and chemokine inter-regulation in the inflamed or injured CNS," Brain Research Reviews, vol. 48, no. 2, pp. 178184, 2005.

[5] Y. Sekine, T. Yumioka, T. Yamamoto et al., "Modulation of TLR4 signaling by a novel adaptor protein signal-transducing adaptor protein-2 in macrophages," Journal of Immunology, vol. 176, no. 1, pp. 380-389, 2006.

[6] K. Takeda and S. Akira, "Roles of Toll-like receptors in innate immune responses," Genes to Cells, vol. 6, no. 9, pp. 733-742, 2001.
[7] B. Bresnihan, "Pathogenesis of joint damage in rheumatoid arthritis," Journal of Rheumatology, vol. 26, no. 3, pp. 717-719, 1999.

[8] G. R. Burmester, B. Stuhlmüller, G. Keyszer, and R. W. Kinne, "Mononuclear phagocytes and rheumatoid synovitis: mastermind or workhorse in arthritis?" Arthritis and Rheumatism, vol. 40, no. 1, pp. 5-18, 1997.

[9] J. A. Gracie, R. J. Forsey, W. L. Chan et al., "A proinflammatory role for IL-18 in rheumatoid arthritis," Journal of Clinical Investigation, vol. 104, no. 10, pp. 1393-1401, 1999.

[10] T. J. Kang, J. S. Moon, S. Lee, and D. Yim, "Polyacetylene compound from Cirsium japonicum var. ussuriense inhibits the LPS-induced inflammatory reaction via suppression of NF$\kappa \mathrm{B}$ activity in RAW 264.7 cells," Biomolecules and Therapeutics, vol. 19, no. 1, pp. 97-101, 2011.

[11] S. Dos Santos Mendes, A. Candi, M. Vansteenbrugge et al., "Microarray analyses of the effects of NF- $\kappa \mathrm{B}$ or PI3K pathway inhibitors on the LPS-induced gene expression profile in RAW264.7 cells. Synergistic effects of rapamycin on LPSinduced MMP9-overexpression," Cellular Signalling, vol. 21, no. 7, pp. 1109-1122, 2009.

[12] K. J. Min, J. T. Lee, E. H. Joe, and T. K. Kwon, "An $\mathrm{I} \kappa \mathrm{B} \alpha$ phosphorylation inhibitor induces heme oxygenase-1(HO-1) expression through the activation of reactive oxygen species (ROS)-Nrf2-ARE signaling and ROS-PI3K/Akt signaling in an NF- $\kappa$ B-independent mechanism," Cellular Signalling, vol. 23, no. 9, pp. 1505-1513, 2011.

[13] H. Lee, C. I. Lin, J. J. Liao et al., "Lysophospholipids increase ICAM-1 expression in HUVEC through a Gi- and NF- $\kappa \mathrm{B}-$ dependent mechanism," American Journal of Physiology, vol. 287, no. 6, pp. C1657-C1666, 2004.

[14] C. Juliana, T. Fernandes-Alnemri, J. Wu et al., "Anti-inflammatory compounds parthenolide and bay 11-7082 are direct inhibitors of the inflammasome," Journal of Biological Chemistry, vol. 285, no. 13, pp. 9792-9802, 2010.

[15] Y. Dai, M. Rahmani, and S. Grant, "Proteasome inhibitors potentiate leukemic cell apoptosis induced by the cyclindependent kinase inhibitor flavopiridol through a SAPK/JNKand NF- $\kappa \mathrm{B}$-dependent process," Oncogene, vol. 22, no. 46, pp. 7108-7122, 2003.

[16] T. J. Won, Y. J. Huh, Y. T. Lim, D. S. Song, and K. W. Hwang, "Effects of anti-b7.1/b7.2 antibodies on lps-stimulated 
macrophages," Biomolecules and Therapeutics, vol. 18, no. 4, pp. 463-468, 2010.

[17] J. Y. Cho, K. U. Baik, J. H. Jung, and M. H. Park, "In vitro antiinflammatory effects of cynaropicrin, a sesquiterpene lactone, from Saussurea lappa," European Journal of Pharmacology, vol. 398, no. 3, pp. 399-407, 2000.

[18] S. I. Lim, C. W. Cho, U. K. Choi, and Y. C. Kim, "Antioxidant activity and ginsenoside pattern of fermented white ginseng," Journal of Ginseng Research, vol. 34, no. 3, pp. 168-174, 2010.

[19] R. Pauwels, J. Balzarini, M. Baba et al., "Rapid and automated tetrazolium-based colorimetric assay for the detection of antiHIV compounds," Journal of Virological Methods, vol. 20, no. 4, pp. 309-321, 1988.

[20] Y. S. Roh, H. B. Kim, C. W. Kang, B. S. Kim, S. Y. Nah, and J. H. Kim, "Neuroprotective effects of ginsenoside Rg3 against 24-OH-cholesterol-induced cytotoxicity in cortical neurons," Journal of Ginseng Research, vol. 34, no. 3, pp. 246-253, 2010.

[21] J. R. Kim, D. R. Oh, M. H. Cha et al., "Protective effect of polygoni cuspidati radix and emodin on Vibrio vulnificus cytotoxicity and infection," Journal of Microbiology, vol. 46, no. 6, pp. 737-743, 2008.

[22] S. E. Byeon, Y. G. Lee, B. H. Kim et al., "Surfactin blocks NO production in lipopolysaccharide-activated macrophages by inhibiting NF- $\kappa \mathrm{B}$ activation," Journal of Microbiology and Biotechnology, vol. 18, no. 12, pp. 1984-1989, 2008.

[23] J. Y. Lee, Y. G. Lee, J. Lee et al., "Akt Cys-310-targeted inhibition by hydroxylated benzene derivatives is tightly linked to their immunosuppressive effects," Journal of Biological Chemistry, vol. 285, no. 13, pp. 9932-9948, 2010.

[24] G. Devitt, M. Thomas, A. M. Klibanov, T. Pfeiffer, and V. Bosch, "Optimized protocol for the large scale production of HIV pseudovirions by transient transfection of HEK293T cells with linear fully deacylated polyethylenimine," Journal of Virological Methods, vol. 146, no. 1-2, pp. 298-304, 2007.

[25] K. K. Jung, H. S. Lee, J. Y. Cho et al., "Inhibitory effect of curcumin on nitric oxide production from lipopolysaccharideactivated primary microglia," Life Sciences, vol. 79, no. 21, pp. 2022-2031, 2006.

[26] Y. O. Kim and S. W. Lee, "Microarray analysis of gene expression by ginseng water extracts in a mouse adrenal cortex after immobilization stress," Journal of Ginseng Research, vol. 35, no. 1, pp. 111-123, 2011.

[27] D. C. Yang, H. Sun, O. R. Lee et al., "Identification of 'chunpoong' among Panax ginseng cultivars using real time PCR and SNP marker," Journal of Ginseng Research, vol. 34, no. 1, pp. 47-50, 2010.

[28] S. Kim, S. Shim, D. S. Choi, J. H. Kim, Y. B. Kwon, and J. Kwon, "Modulation of LPS-stimulated astroglial activation by ginseng total saponins," Journal of Ginseng Research, vol. 35, no. 1, pp. 80-85, 2011.

[29] V. Malladi, M. Puthenedam, P. H. Williams, and A. Balakrishnan, "Enteropathogenic Escherichia coli outer membrane proteins induce iNOS by activation of NF- $\kappa \mathrm{B}$ and MAP kinases," Inflammation, vol. 28, no. 6, pp. 345-353, 2004.

[30] M. G. García, L. Alaniz, E. C. Lopes, G. Blanco, S. E. Hajos, and E. Alvarez, "Inhibition of NF- $\kappa$ B activity by BAY 117082 increases apoptosis in multidrug resistant leukemic T-cell lines," Leukemia Research, vol. 29, no. 12, pp. 1425-1434, 2005.

[31] S. Dos Santos, A. I. Delattre, F. De Longueville, H. Bult, and M. Raes, "Gene expression profiling of LPS-stimulated murine macrophages and role of the NF- $\kappa \mathrm{B}$ and PI3K/mTOR signaling pathways," Annals of the New York Academy of Sciences, vol. 1096, pp. 70-77, 2007.
[32] A. Cloutier, T. Ear, E. Blais-Charron, C. M. Dubois, and P. P. McDonald, "Differential involvement of NF- $\kappa$ B and MAP kinase pathways in the generation of inflammatory cytokines by human neutrophils," Journal of Leukocyte Biology, vol. 81, no. 2, pp. 567-577, 2007.

[33] X. Meng, M. A. Martinez, M. A. Raymond-Stintz, S. S. Winter, and B. S. Wilson, "IKK inhibitor bay 11-7082 induces necroptotic cell death in precursor-B acute lymphoblastic leukaemic blasts," British Journal of Haematology, vol. 148, no. 3, pp. 487-490, 2010.

[34] S. Qin and P. B. Chock, "Implication of phosphatidylinositol 3-kinase membrane recruitment in hydrogen peroxideinduced activation of PI3K and Akt," Biochemistry, vol. 42, no. 10, pp. 2995-3003, 2003.

[35] B. D. Cuevas, Y. Lu, M. Mao et al., "Tyrosine Phosphorylation of p85 Relieves Its Inhibitory Activity on Phosphatidylinositol 3-Kinase," Journal of Biological Chemistry, vol. 276, no. 29, pp. 27455-27461, 2001.

[36] Y. Zhao and V. Natarajan, "Lysophosphatidic acid signaling in airway epithelium: role in airway inflammation and remodeling," Cellular Signalling, vol. 21, no. 3, pp. 367-377, 2009.

[37] L. Malmgaard, "Induction and regulation of IFNs during viral infections," Journal of Interferon and Cytokine Research, vol. 24, no. 8, pp. 439-454, 2004.

[38] M. H. Kim, D. S. Yoo, S. Y. Lee et al., "The TRIF/TBK1/IRF-3 activation pathway is the primary inhibitory target of resveratrol, contributing to its broad-spectrum anti-inflammatory effects," Pharmazie, vol. 66, no. 4, pp. 293-300, 2011.

[39] B. Dawn, Y. T. Xuan, Y. Guo et al., "IL-6 plays an obligatory role in late preconditioning via JAK-STAT signaling and upregulation of iNOS and COX-2," Cardiovascular Research, vol. 64, no. 1, pp. 61-71, 2004.

[40] K. Clark, L. Plater, M. Peggie, and P. Cohen, "Use of the pharmacological inhibitor BX795 to study the regulation and physiological roles of TBK1 and $\mathrm{I} \kappa \mathrm{B}$ Kinase $\varepsilon$ : A distinct upstream kinase mediates ser-172 phosphorylation and activation," Journal of Biological Chemistry, vol. 284, no. 21, pp. 14136-14146, 2009.

[41] E. Nassar, H. A. Abdel-Aziz, H. S. Ibrahim, and A. M. Mansour, "Synthesis of diarylpyrazoles containing a phenylsulphone or carbonitrile moiety and their chalcones as possible anti-inflammatory agents," Scientia Pharmaceutica, vol. 79, no. 3, pp. 507-524, 2011.

[42] J. J. Chen, Y. C. Tsai, T. L. Hwang, and T. C. Wang, "Thymol, benzofuranoid, and phenylpropanoid derivatives: antiinflammatory constituents from Eupatorium cannabinum," Journal of Natural Products, vol. 74, no. 5, pp. 1021-1027, 2011.

[43] T. Yu, J. Shim, Y. Yang et al., "3-(4-(tert-Octyl)phenoxy)propane-1,2-diol suppresses inflammatory responses via inhibition of multiple kinases," Biochemical Pharmacology, vol. 83, no. 11, pp. 1540-1551, 2012. 


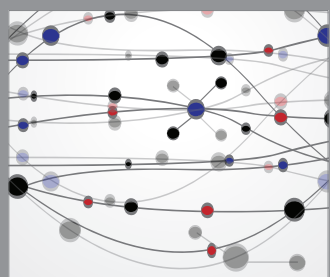

The Scientific World Journal
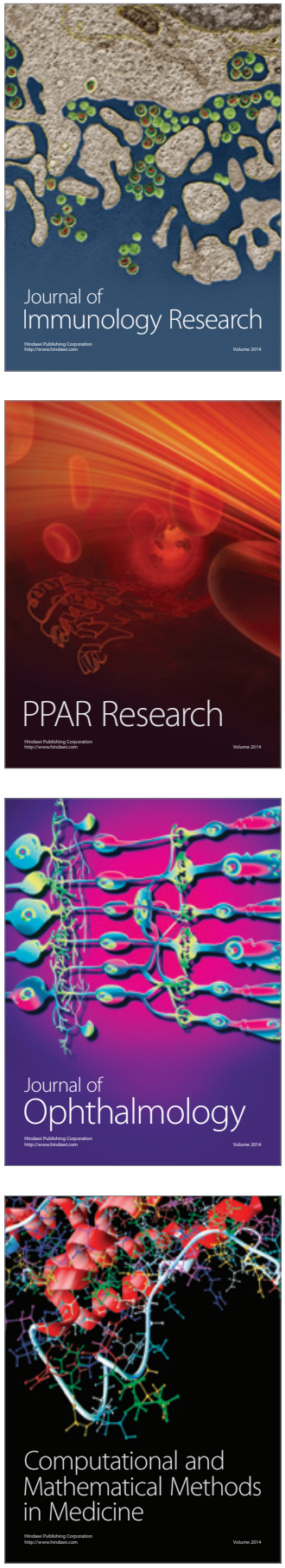

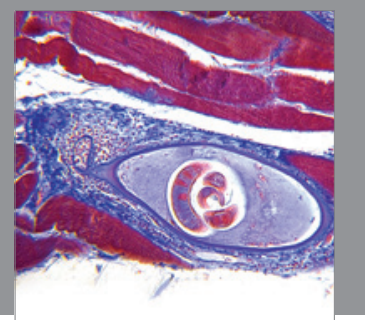

Gastroenterology

Research and Practice
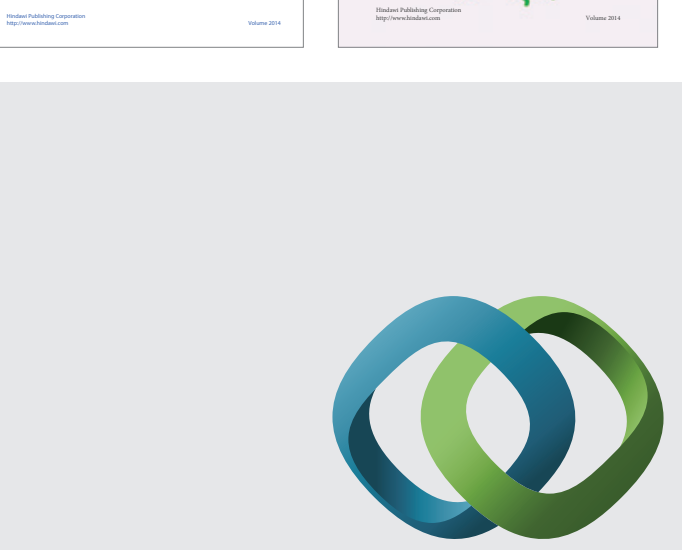

\section{Hindawi}

Submit your manuscripts at

http://www.hindawi.com
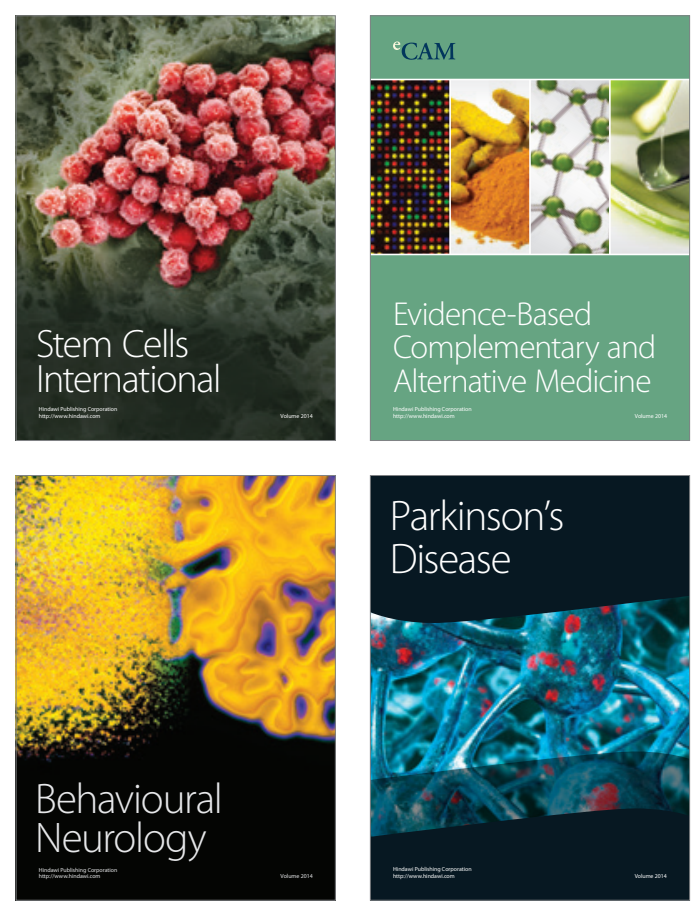

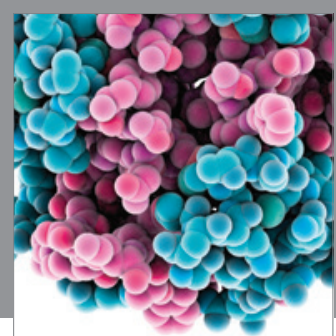

Journal of
Diabetes Research

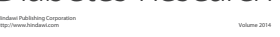

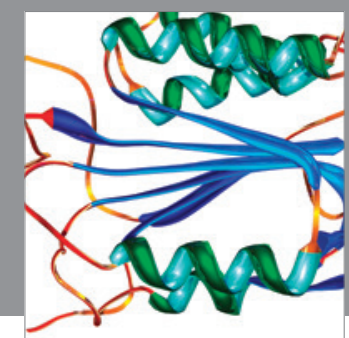

Disease Markers
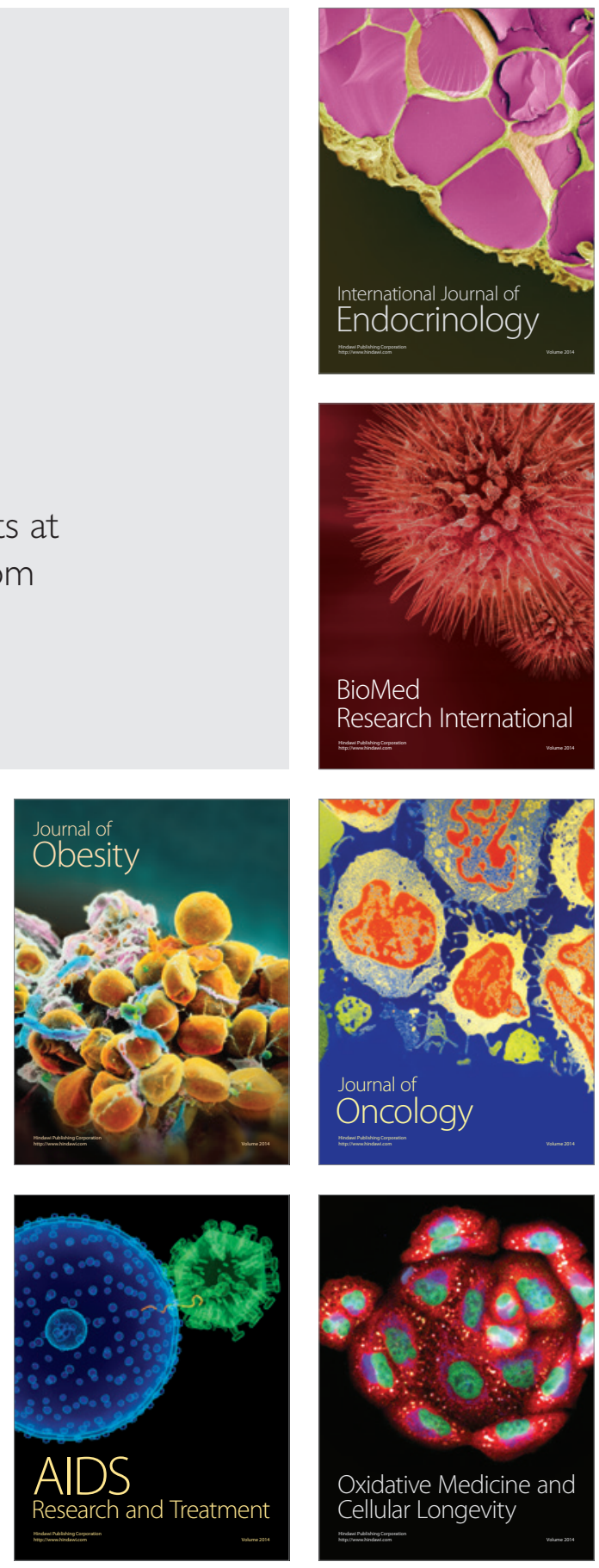